\title{
Impact of Humble Leadership on the Boundary Spanning Behavior
}

\author{
Jing Lv, Zhihua Deng* \\ School of Business Administration, Guizhou University of Finance and Economics, Guiyang, Guizhou, \\ China
}

Keywords: Humble leadership, Team boundary spanning behavior, Team psychological safety

\begin{abstract}
This paper discussed the impact mechanism of humble leadership to the team boundary spanning behavior, examined the mediating role of team psychological processes. Based on the statistical analysis of questionnaire data, the results showed that: (1) Humble leadership has a positive influence on team boundary spanning behavior. (2) Team psychological safety has full mediation effect between the relationship of humble leadership and team boundary spanning behavior. Research conclusions expanded the empirical effect of humble leadership in the team level and the dynamic mechanism of team boundary spanning behavior in the Chinese organizational situation, which provided many theoretical references and managerial revelations for the R\&D team leader to practice humility leadership behavior or effectively promote team boundary spanning behavior.
\end{abstract}

\section{Introduction}

In the fierce business competition, enterprises increasingly rely on the R\&D team as the carrier of innovation to enhance the core competitiveness. $R \& D$ teams need to keep close track of changes in technology frontiers and market trends, and often need to cross their own boundaries and perform team boundary spanning behavior to access critical resources that needed for R\&D $[1,2]$. Team research based on closed system fails to explore and solve the problem of how the team obtains key resources from the outside, and starts to treat the R\&D team as an open system [1-3]. The important question that follows is, how can the R\&D team effectively drive the team boundary spanning behavior?

\section{Theories and Hypothesis}

\subsection{Humble leadership and team boundary spanning behavior}

Humble leadership, the leaders assess themselves objectively and accurately in order to meet real and comprehensive selves, be good at discovering the advantage of employees, appreciate the contributions of others actively, seek advice with an open attitude, learn a lot with an open mind, and to achieve the effectiveness of leadership by a way of example in teachability [4], including three dimensionalities: looking at yourself objectively, appreciation of others and teachability [5]. Team boundary spanning behavior (TBSB), play the role of crossover subject for undertaking mission to establish a relationship with the outside and interactive behavior [6], containing three dimensionalities: envoy behavior, task coordination behavior and detection behavior [1,2,7]. Foreign representative team and envoys behavior such as exercise publicity or public relations, and associated institutions in business negotiate or goods trading exercise the task coordination behavior, and find out policy trends or detect rivals such as detection behavior, tend to increase the workload of R\&D team, create cognitive ambiguity and role conflict among team members, result in increase of work stress and anxiety [6]. Humble leadership have a good sense of self-awareness, can be objective and accurate to view of the self [4], which can help team members to form objective cognition and accept their own limitations and shortcomings, so as to reduce and overcome negative emotion and psychology in spanning behavior [8]. Thus: Hypothesis1(H1): humble leadership has a positive influence on team boundary spanning behavior. 


\subsection{Mediating role of team psychological security}

Team psychological safety (TPS) is the shared belief of team to ensure the safety of interpersonal relationship risk [9]. First, humble leadership has a positive impact on team psychological safety. Team psychological safety greatly depends on the social information acquired by team members [10]. As the key social information source in the work situation, the leader has an important influence on the team psychological safety [9]. Humble leadership appreciate and recognize the value of team members [11], treat subordinates with respect and fairness [12], which can eliminate the anxiety of team members and reduce their risk perception, so that the security of the whole team has a reliable guarantee. Then, team psychological safety can buffer the risks caused by the team interaction with the outside world and reduce the impact and interference brought by environmental uncertainty to the team, it means that team members in persuading the outside world to provide necessary support for the team, regardless of interpersonal risk within the team. Utilize the limited time and energy to protect team from the impact of the external pressure, have important effect on team boundary spanning behavior $[9,13,14]$. Thus: Hypothesis1(H2): team psychological safety has mediation effect between the relationship of humble leadership and team boundary spanning behavior.

In conclusion, the conceptual model of this paper is shown in figure 1.

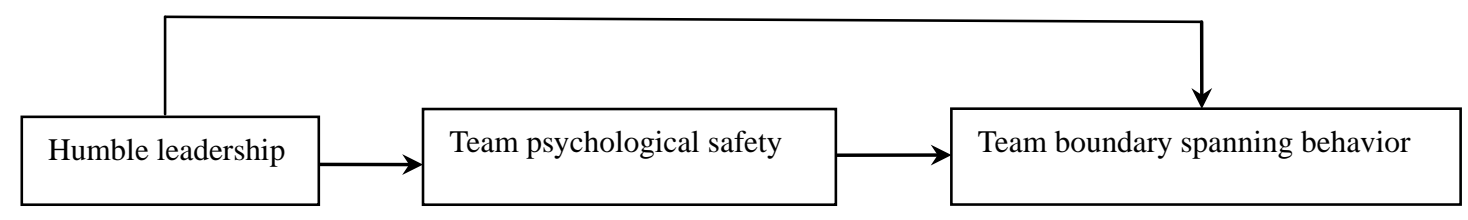

Figure 1 research model.

\section{Research Design}

\subsection{Investigation process}

Data collection is conducted in the way of team leader-team member matching survey. Investigated the team leader and formal members respectively. The samples were collected from the R\&D teams of 23 enterprises in Shanghai, Shenzhen, Nanjing, Xi 'an, Chengdu and Guiyang. A total of 122 team leaders and 378 team members were sent questionnaires, also 91 and 296 corresponding questionnaires were collected, with a recovery rate of $74.59 \%$ and $78.30 \%$. After eliminated invalid questionnaires, the corresponding data of 78 team leaders and 283 team members were finally obtained.

\subsection{Measurement of variables}

Humble leadership adopt the three-dimensional scale developed by Owens, Johnson and Mitchell (2013) [5], whose cronbach $\alpha$ is 0.85 . Team psychological safety use a single-dimensional scale developed by Edmondson (1999) [9], and the cronbach $\alpha$ of this scale is 0.84. The three-dimensional scale used by Ancona and Caldwell (1992) [1] adopts for team boundary spanning behavior, and the cronbach $\alpha$ of this scale was 0.78 . Control variables include team leaders' gender, age and education level, as well as the team time and scope. The questionnaire adopts LIKERT scale, seven-point scale, "1" represented "strongly disagree", "7" represented "strongly agree".

\section{Data Analysis}

\subsection{Descriptive statistics}

Most of the research objects were men, the team leaders of men accounted for $70.14 \%$, the team members of men accounted for $74.9 \%$, The age of the team leaders focused between 31 to 50 years 
old, accounted for $74.9 \%$, most of the team members were under the age of 40 , accounted for $75.33 \%$.As the research objects were the $R \& D$ team, the education level of the team leaders and the members were mostly university culture and above, accounted for $86.58 \%$ and $88.72 \%$ respectively.

\subsection{Correlation analysis}

Table 1 summarizes the mean, standard deviation, and correlation coefficients among the variables. Humble leadership is positively correlated with team psychological safety $(\mathrm{r}=0.470$, $\mathrm{p}<0.01)$ and team boundary spanning behavior $(\mathrm{r}=0.421, \mathrm{p}<0.01)$. There is a significant positive correlation between team boundary spanning behavior and team psychological safety $(\mathrm{r}=0.418$, $\mathrm{p}<0.01)$.

Table 1 Mean, standard deviation and correlation coefficient of variables.

\begin{tabular}{|c|c|c|c|c|c|c|c|}
\hline Variables’ name & Mean & $\begin{array}{c}\text { Standard } \\
\text { deviation }\end{array}$ & Gender & Age & $\begin{array}{c}\text { Education } \\
\text { background }\end{array}$ & 1 & 2 \\
\hline Gender- leadership & 0.204 & 0.468 & & & & & \\
\hline Age- leadership & 1.284 & 0.749 & 0.257 & & & & \\
\hline $\begin{array}{c}\text { Education-leadership } \\
\text { Humble leadership }\end{array}$ & 2.847 & 0.486 & 0.245 & $-0.254^{*}$ & & & \\
\hline $\begin{array}{c}\text { Team psychological } \\
\text { safety }\end{array}$ & 5.154 & 0.845 & 0.286 & 0.354 & $0.254^{*}$ & $0.470^{* *}$ & \\
\hline $\begin{array}{c}\text { Team boundary } \\
\text { spanning behavior }\end{array}$ & 4.847 & 1.257 & 0.407 & 0.308 & $-0.209^{* *}$ & $0.421^{* *}$ & $0.418^{* *}$ \\
\hline
\end{tabular}

\subsection{Confirmatory factor analysis}

LISREL8.70 software was adopted to analyze the discriminant validity of the scale by using the method of confirmatory factor analysis. Table2, assuming five-factors model has the best goodness of fit, $\chi 2 / \mathrm{d} f=2.158, \mathrm{AGFI}=0.931$, RMSEA=0.081, NNFI $=0.964, \mathrm{CFI}=0.919$, SRMR=0.041, other alternative models have poor fit, indicating that there is a good discrimination validity among the three variables.

Table 2 Confirmatory factor analysis of discrimination validity of scale.

\begin{tabular}{|c|c|c|c|c|c|c|}
\hline Model & $\chi 2 / \mathrm{d} f$ & AGFI & RMSEA & NNFI & CFI & SRMR \\
\hline Three-factor model: HL+ TPS,TBSB & 10.458 & 0.485 & 0.241 & 0.748 & 0.658 & 0.124 \\
\hline Two-factor model: HL,TPS +TBSB & 10.487 & 0.384 & 0.305 & 0.527 & 0.600 & 0.241 \\
\hline Single-factor model: HL+ TPS+TBSB & 13.157 & 0.235 & 0.334 & 0.535 & 0.845 & 0.147 \\
\hline
\end{tabular}

\subsection{Cluster analysis}

Two variables in this paper are team level variables and are reported by individuals in the team, therefore, it is necessary to cluster the data reported by individuals into data at the team level, intra group-consistency (RWG) and intra group-correlation ICC(1) and ICC(2) of cluster variables need to be tested. Which indicate that data aggregation is ideal, if RWG is greater than 0.7 , ICC 1 is greater than 0.10 , and ICC 2 is greater than 0.7 [15], the specific values of each variable are shown in table 3.

Table 3 Scale value of Aggregation analysis.

\begin{tabular}{|c|c|c|c|}
\hline Variables & Rwg & ICC (1) & ICC (2) \\
\hline Humble Leadership & 0.75 & 0.23 & 0.78 \\
\hline Team psychological safety & 0.76 & 0.18 & 0.76 \\
\hline
\end{tabular}

It can be seen from table 3 that the RWG of both variables are greater than 0.70 , and the ICC (1) 
is greater than 0.1 , the ICC (2) is greater than 0.70 , indicate that the measured variables meet the requirements of data aggregation.

\subsection{Hypothesis testing}

By constructing a nested model to test the main effect and mediation effect, the results are summarized in table 4. According to model 3, without considering the role of intermediary variables in team psychological safety, humble leadership has a positive influence on team boundary spanning behavior $(\beta=0.392, \mathrm{p}<0.01)$, H1 is verified. Moreover, humble leadership has a positive influence on team psychological $\operatorname{safety}(\beta=0.376, p<0.001)$. Comparing model 3 with model 1 , considering the role of intermediary variables in team psychological safety, the effect of humble leadership on team boundary spanning behavior is no longer $\operatorname{significant}(\beta=0.031, p>0.05)$, and team psychological safety has a positive influence on team boundary spanning behavior $(\beta=0.203, p$ $<0.01)$. Through the above comparison, team psychological safety has full mediation effect between the relationship of humble leadership and team boundary spanning behavior, $\mathrm{H} 2$ is verified.

Table 4 Results of structural equation model analysis.

\begin{tabular}{|c|c|c|c|c|}
\hline & & model 1 & model 2 & model 3 \\
\cline { 3 - 5 } & & $\begin{array}{c}\text { HL } \rightarrow \text { TPS } \rightarrow \text { TBSB } \\
\text { HL } \rightarrow \text { TBSB }\end{array}$ & HL $\rightarrow$ TPS $\rightarrow$ TBSB & $\begin{array}{c}\text { HL } \rightarrow \text { TPS } \\
\text { HL } \rightarrow \text { TBSB }\end{array}$ \\
\hline \multirow{4}{*}{$\begin{array}{c}\text { Standardized } \\
\text { Coefficients }\end{array}$} & HL $\rightarrow$ TPS & $0.305^{* *}$ & $0.378^{* *}$ & $0.376^{* *}$ \\
\cline { 2 - 5 } & TPS $\rightarrow$ TBSB & $0.203^{* *}$ & $0.335^{* *}$ & \\
\cline { 2 - 5 } $\begin{array}{c}\text { foodness of } \\
\text { model }\end{array}$ & HL $\rightarrow$ TBSB & 0.031 & & $0.392^{* *}$ \\
\cline { 2 - 5 } & AG/d $f$ & 3.258 & 2.354 & 4.528 \\
\cline { 2 - 5 } & RMSEA & 0.815 & 0.948 & 0.761 \\
\cline { 2 - 5 } & NNFI & 0.847 & 0.076 & 0.168 \\
\cline { 2 - 5 } & CFI & 0.847 & 0.945 & 0.687 \\
\cline { 2 - 5 } & SRMR & 0.075 & 0.038 & 0.084 \\
\hline
\end{tabular}

\section{Conclusion}

This paper discussed the impact mechanism of humble leadership to the team boundary spanning behavior, examined the mediating role of team psychological processes. The results showed that: (1) humble leadership has a positive influence on team boundary spanning behavior. (2) team psychological safety has full mediation effect between the relationship of humble leadership and team boundary spanning behavior. This study responds to the call of academic circles for strengthening the multi-level influence study of leaders' humility traits or behavior [16,17], it also expands the research on humble leadership team. Thus Therefore, leaders of R\&D teams should actively shape their own humility and behavior, acknowledge that the team benefits from the expertise of its members, appropriately enlarge the advantages of team members and strive to find the contribution of team members in team boundary spanning behavior, so as to encourage them to carry out team boundary spanning behavior effectively, and then to improve team performance and enterprise competitiveness.

\section{Acknowledgments}

Supported by the National Natural Science Foundation of China (71962003). 


\section{References}

[1] Ancona D G, Caldwell D F. Bridging the boundary: external activity and performance in organizational teams. Administrative Science Quarterly, 1992, 37(4): 634-665.

[2] Marrone, J A. Team boundary spanning: a multilevel review of past research and proposals for the future. Journal of Management, 2010, 36(4): 911-940.

[3] Choi, J N. External activities and team effectiveness review and theoretical development. Small Group Research, 2002, 33(2): 181-208.

[4] Owens B P, Hekman D R. Modeling how to grow: an inductive examination of humble leader behaviors, contingencies, and outcomes. Academy of Management Journal, 2012, 55(4): 787-818.

[5] Owens B P, Johnson M D, Mitchell T R. Expressed humility in organizations: implications for performance, teams, and leadership. Organization Science, 2013, 24(5): 1517-1538.

[6] Marrone, J A, Tesluk, P E, Carson, J B. A multi-level investigation of antecedents and consequences of team member boundary spanning behavior. Academy of Management Journal, 2007 (50), 1423-1439.

[7] Yuan Qinghong, Zhang Hualei, Wang Zhen, Huang Yong. The double-edged sword effect of team boundary spanning activities on innovation performance in R\&D teams: the mediating role of team reflexivity and the moderating role of empowering leadership. Nankai Business Review, 2015, 18(3): 13-23.

[8] Gu Q, Wang G G, Wang L. Social capital and innovation in R\&D teams: the mediating roles of psychological safety and learning from mistakes. R\&D Management, 2013, 43(2): 89-102.

[9] Edmondson A. C. Psychological safety and learning behavior in work teams. Administrative Science Quarterly, 1999, 44(2): 350-383.

[10] Piccolo, R F, Colquitt, J A. Transformational leadership and job behaviors: the mediating role of core job characteristics. Academy of Management Journal, 2006, 49(2): 327-340.

[11] Owens B P, Wallace A S, Waldman D A. Leader narcissism and follower outcomes: the counterbalancing effect of leader humility. Journal of Applied Psychology, 2015, 100(4): 1203-1213.

[12] Ou A. Y, Tsui A S, Kinicki A J, et al. Humble chief executive officers' connections to top management team integration and middle managers' responses. Administrative Science Quarterly, 2014, 59(1): 34-72.

[13] Xue Huijuan. Review and prospect of research on the team boundary-spanning behavior. Foreign Economics \&Management. 2010(9): 10-15.

[14] Zhang Dali, Ge Yuhui. Relationship between top management team boundary-spanning behavior and the innovation performance of enterprises: a perspective of team learning. Journal of Systems \& Management. 2016(2): 235-245.

[15] Bliese, P D. Within-group agreement, non-independence, and reliability: implications for data aggregation and analysis, Klein K J, Kozlowski S W. Multilevel theory, research, and methods in organizations: foundations, extensions and new directions. San Francisco: Jossey-Bass, 2000.

[16] Cannella, A. A, Holcomb T R. A multilevel analysis of the upper-echelon model. In A. Dansereau, and F. J. Yammarino (eds.), Research in multi-level issues: multi-level issues in strategy and methods: 2005, 197-237. Oxford, U.K.: Elsevier.

[17] Yukl, G. How leaders influence organizational effectiveness. Leadership Quarterly, 2008 (19): 708-722. 